\title{
ECOLOGICAL ADVANCED INNOVATION DESIGN APPROACH FOR EFFICIENT INTEGRATED UPSTREAM AND DOWNSTREAM PROCESSES
}

\author{
Livotov, Pavel (1); Mas'udah, Mas'udah (1); Chandra Sekaran, Arun Prasad (1); Law, Richard \\ (2); Reay, David (3)
}

1: Offenburg University of Applied Sciences, Germany; 2: Newcastle University, United Kingdom; 3: David Reay \& Associates, United Kingdom

\begin{abstract}
Process engineering industries are now facing growing economic pressure and societies' demands to improve their production technologies and equipment, making them more efficient and environmentally friendly. However unexpected additional technical and ecological drawbacks may appear as negative side effects of the new environmentally-friendly technologies. Thus, in their efforts to intensify upstream and downstream processes, industrial companies require a systematic aid to avoid compromising of ecological impact. The paper conceptualises a comprehensive approach for eco-innovation and ecodesign in process engineering. The approach combines the advantages of Process Intensification as Knowledge-Based Engineering (KBE), inventive tools of Knowledge-Based Innovation (KBI), and main principles and best-practices of Eco-Design and Sustainable Manufacturing. It includes a correlation matrix for identification of eco-engineering contradictions and a process mapping technique for problem definition, database of Process Intensification methods and equipment, as well as a set of strongest inventive operators for eco-ideation.
\end{abstract}

Keywords: Ecodesign, Design process, Knowledge-based innovation, Process intensification, Integrated product development

Contact:

Livotov, Pavel

Offenburg University of Applied Sciences

Mechanical and Process Engineering

Germany

pavel.livotov@hs-offenburg.de

Cite this article: Livotov, P., Mas'udah, M., Chandra Sekaran, A.P., Law, R., Reay, D. (2019) 'Ecological Advanced

Innovation Design Approach for Efficient Integrated Upstream and Downstream Processes', in Proceedings of the 22nd International Conference on Engineering Design (ICED19), Delft, The Netherlands, 5-8 August 2019. DOI:10.1017/

dsi.2019.336 


\section{INTRODUCTION}

Economic growth and ecological problems motivate industries to apply eco-friendly technologies and equipment. The major negative implication of the technological progress in process engineering is attributable to the environmental impact. According to the European Commission the process industry operations for downstream processing are responsible for up to $45 \%$ of the energy consumption and represent today on average $50-60 \%$ of the total capital and operating costs, which are often linked to the inefficiencies in the upstream processes. Thus, technological innovations in upstream and downstream unit operations could deliver significant advances in resource and energy efficiency (European Commission, 2018).

Numerous approaches, methods and tools have been developed in the last three decades to support sustainable and environmentally-friendly product and process development. Among the wellestablished ones belongs the concept of Eco-Design, which is defined by the International Standard Organisation (ISO 14006:2011) as "integration of environmental aspects into product design and development, with the aim of reducing adverse environmental impacts throughout a product's life cycle". The eco-innovation focuses on the integration of environmental aspects and requirements in the early stages of the innovation and new product development processes. In accordance to (Fussler and James, 1996), eco-innovation can be defined as a process for new product or technology development that provides significant environmental advantages. The ISO issued numerous norms, guidelines, and tools to maintain Eco-Design. For example, ISO14040:2006 describes the principles and framework for life cycle assessment (LCA), ISO14044:2006 provides LCA guidelines, and ISO14006:2011 provides guidelines to implement Eco-Design as part of an environmental management system (EMS) within companies. A comparative study of strategy- and ideation-oriented eco-innovation tools is presented in (Tyl et al., 2014). A recent extensive literature review published by the authors (Livotov et al., 2019c) mentions in the field of eco-innovation in process engineering in the first place Green Process Engineering (Poux et al., 2016), Process Intensification (Boodhoo and Harvey, 2013), and Process Design for Sustainability (Azzaro-Pantel, 2015).

Since 2000 the Theory of Inventive Problem Solving TRIZ (Altshuller, 1984; VDI 2016) has been applied for development of cleaner and eco-friendly production processes. A comparison of 28 ecodesign methods and tools by (Lindahl and Ekermann, 2013) attests TRIZ the average level of complexity and time expenditures for its application but outlines no built-in life cycle perspective in TRIZ. As an example of a successful TRIZ adaptation in eco-design, one should mention the system of eco-innovation guidelines including more than 330 operators for problem definition and ideation (Russo, Schofer et al., 2015). Other researchers proposed to apply TRIZ for the domain of ecoinnovation in the chemical industry (Ferrer et al., 2012), for environment-friendly cleaner manufacturing (Fresner et al., 2010) or for design of green products (Chen, 2002). The authors of this paper identify in their systematic review (Livotov et al., 2019c) 66 papers on eco-innovation methods using TRIZ elements or adaptions, published between 2000 and 2018. This review outlines that the ideation potential of classical TRIZ has been successfully tested in eco-design, but the analytical TRIZ tools for problem definition and identification of engineering contradictions such as Root-Conflict Analysis, Cause-Effect-Chain-Analysis, or Anticipatory Failure Identification seem to be still underestimated. No significant progress has been reported regarding application of the functionoriented search (FOS) and data mining approaches in eco-innovation. There is also no systematic adaptation or further development of TRIZ tools for comprehensive eco-innovation in the field of process engineering with a life-cycle view.

Recent publications report on the advances in eco-friendly integrated upstream and downstream processes such as, for example, improved downstream processes through continuous operation and system automation (GE Healthcare, 2016), eco-efficient downstream bio-processing using a novel intensified separation technique (Patrascu et al., 2018) and others (Wang et al., 2017).

However, implementation of new technologies in process engineering often leads to additional technical and environmental problems (Benali and Kudra, 2008; Russo and Serafini, 2015). Moreover, even if new solutions propose an eco-friendly product design or process, additional environmental problems still can appear as negative side effects of obtained solutions, creating secondary eco-engineering contradictions (Livotov et al, 2019c). Applying or developing eco-friendly technologies may be a significant challenge for companies because it often requires the acquisition of new resources and competences (Calza et al., 2017). 
Therefore, new technologies in process engineering still demand innovative efforts to reduce environmental issues while increasing economic and technical benefits.

This paper conceptualises a comprehensive approach for eco-innovation and eco-design in process engineering for efficient integrated upstream and downstream processes. The approach combines the advantages of Process Intensification (PI) as a Knowledge-Based Engineering (KBE) methodology, inventive tools of Knowledge-Based Innovation (KBI) with TRIZ, and main principles and bestpractices of Eco-Design and Sustainable Manufacturing.

The paper explains a process mapping technique for problem definition, and a correlation matrix for identification of eco-engineering contradictions. It proposes a re-organised database of Process Intensification methods and equipment for eco-innovation and recommends TRIZ-based inventive operators for systematic solving of specific environmental problems in process engineering. Finally, it defines a future research agenda in the field of eco-innovation methodology in process engineering.

\section{ECOLOGICAL ADVANCED INNOVATION DESIGN APPROACH FOR PROCESS ENGINEERING}

The Advanced Innovation Design Approach (AIDA) in the field of process engineering has been conceptualised in the context of the EU research project "Intensified by Design - Platform for the intensification of processes involving solids handling" within the international consortium of 22 universities, research institutes and industrial companies under the H2020 SPIRE programme (Casner and Livotov, 2017). AIDA can be considered as a mindset with an individually adaptable range of the strongest innovation design techniques. These include a comprehensive front-end innovation process, advanced innovation methods, best tools and methods of the theory of inventive problem solving TRIZ, systematic approaches to design (Pahl \& Beitz, 1996), organisational measures for accelerating innovation, and IT-solutions for Computer-Aided Innovation, among other innovation design methods, elaborated over the last decade in the industry and academia, for example (de Bont et al., 2013).

The general structure of the AIDA concepts in the field of sustainable technological eco-innovation is illustrated in the Figure 1. The ecological AIDA (Eco-AIDA, for short) benefits from the synergies of its three main pillars - Knowledge-Based Engineering, Knowledge-Based Innovation and Eco-Design with Sustainable Manufacturing. In this context the Knowledge-Based Engineering and KnowledgeBased Innovation can be defined as computer-aided methodologies and techniques for capturing, storing, processing, retrieving, presenting and re-use of engineering and innovation knowledge. KBE and KBI, supported by advanced computer algorithms, tools of computer-aided engineering, semantic data processing and artificial intelligence, can dramatically reduce time and effort to model and optimise existing, and to create new, equipment and processes. Even if the borders of these three components are rather fuzzy, the extraction of the manageable number of tools and methods for the eco-innovation process constitutes one of the main Eco-AIDA objectives.

To the major Eco-AIDA contributions and research questions, which have received little or no attention in the research literature on eco-innovation in process engineering to date, belong

- the extended qualitative and quantitative assessment of the PI-technologies with numerous ecological criteria and additional engineering criteria (Section 2.1),

- identification of the strongest inventive operators for different eco-problems in process intensification technologies and equipment, as exemplarily presented in Section 2.2 for reduction of energy consumption and losses,

- creation of a library of cross-industry and interdisciplinary eco-tools, best-practices and examples for their application in process intensification and engineering (Section 2.3),

- development of the computer-aided methods for early identification of environmental problems and secondary eco-contradictions in new process technologies, such as correlation matrix of ecorequirements (Section 3.1), process mapping and eco-problem ranking techniques (Section 3.2).

Finally, the Eco-AIDA implementation in companies should help to establish or to improve their ecoinnovation process. The AIDA eco-innovation process with self-diagnostics, self-optimization, and intelligent information processing and communication, comprises the following typical phases: identification of the needs and problems with high eco-potential, formulation of eco-innovation strategies, identification of eco-engineering contradictions, systematic idea generation and problem solving, evaluation and enhancement of solution ideas, creation of eco-innovation concepts based on solution ideas, followed by evaluation, optimization and implementation of the eco-innovation concepts. 


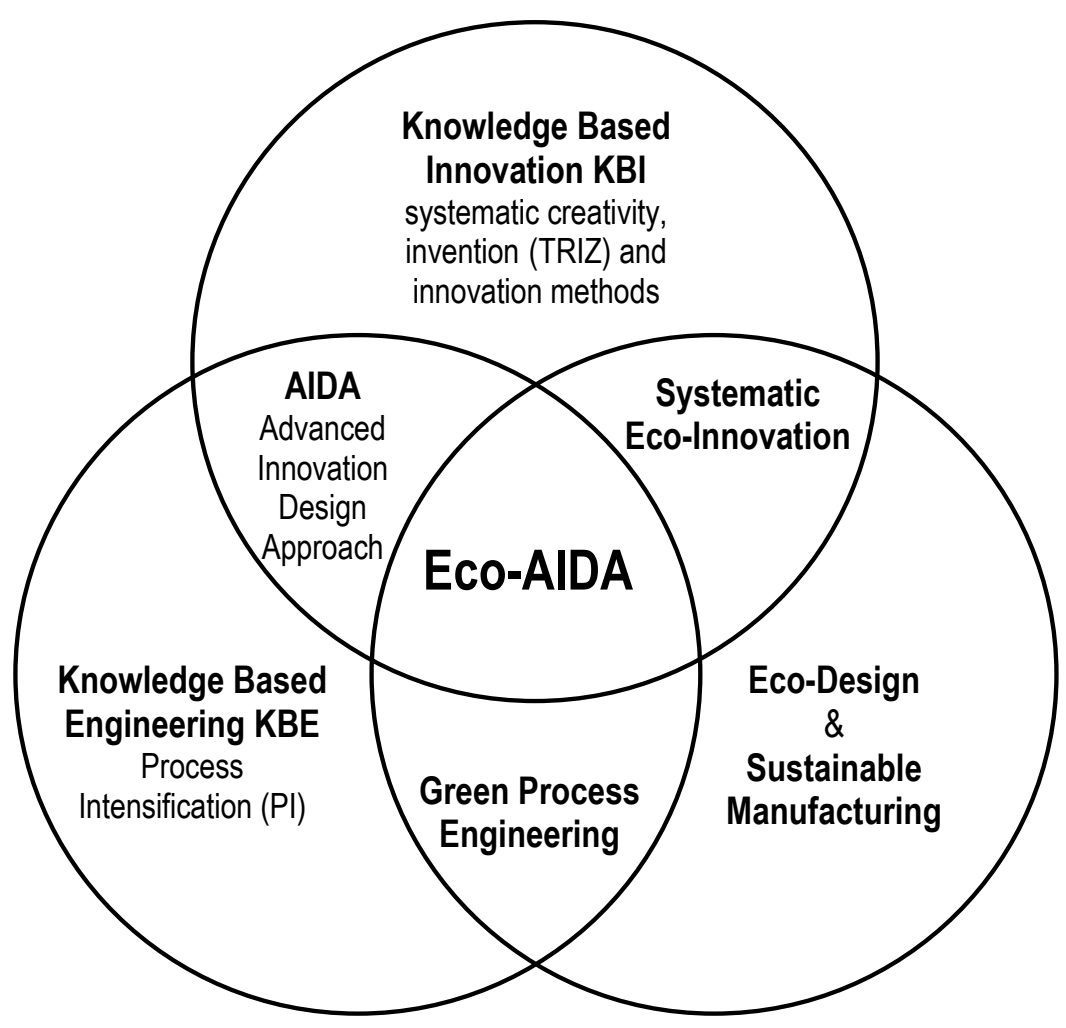

Figure 1. Concept of the ecological Advanced Innovation Design Approach (Eco-AIDA)

\subsection{Process intensification as a part of the Knowledge-Based Engineering}

Process Intensification (PI) can be generally defined as a knowledge-based methodology leading to more efficient processes, equipment and plant design, characterised by reduced energy consumption and losses, raw material and cost reduction, increased process flexibility, quality, safety, and better environmental performance (Boodhoo and Harvey, 2013). The concept of Process Intensification dates back to the research of Prof. Ramshaw and his colleagues (Cross and Ramshaw, 1986; Reay et al., 2013) and subsequently became more diverse in its implementation and practice, from processes mainly involving gas/liquid systems to the handling of solids (Wang et al., 2017). Its modern application is not only limited to chemical engineering and now includes environmental aspects of process engineering (Boodhoo and Harvey, 2013) and challenges of heat and mass transfer in other sectors (Law et al., 2017).

The PI technological databases are continuously evolving and currently cover a wide range of more than 155 processing methods and equipment, such as equipment carrying out chemical reactions, operations not involving chemical reactions, multifunctional reactors, hybrid separation methods, alternative energy sources and others (Boodhoo and Harvey, 2013; Wang et al., 2017). Existing PI databases with intensified equipment types, methods and applications enable engineers to identify and implement the appropriate process-intensifying solution faster in accordance with the objectives and constraints of their development tasks. Table 1 illustrates a fragment of PI-technologies with high potential for energy saving from the qualitative PI assessment presented in the European Roadmap for PI 2007 (Keil, 2018). As the evaluation of the European PI Roadmap contains only 2 ecological parameters, the extended qualitative and quantitative assessment of the PI-technologies in Eco-AIDA will be performed with at least 14 ecological categories and 25 additional engineering criteria, such as energy consumption, air pollution, acidification, safety risks, chemical waste disposal, depletion of abiotic resources, toxicity, eutrophication, photochemical oxidation, water pollution, solid waste, radioactivity, ozone layer depletion, raw material intensity and others. These eco-categories and engineering criteria have been identified by the authors through a comprehensive analysis of 200 patents and 58 process intensification technologies in the field of eco-innovation and process engineering as presented in detail in (Livotov et al., 2019c). Optionally, a combinatorial multiobjective optimization helps to find optimum between the evaluated process intensification solutions (Casner and Livotov, 2017). 
Table 1. Expert assessment of the PI technologies in the European Roadmap for PI 2007; fragment, adapted from (Keil, 2018)

\begin{tabular}{|l|l|l|l|l|}
\hline N. & Process Intensification equipment or method & $\begin{array}{l}\text { Potential for } \\
\text { energy } \\
\text { savings }\end{array}$ & $\begin{array}{l}\text { Potential to } \\
\text { reduce CO } \\
\text { emission }\end{array}$ & $\begin{array}{l}\text { Cost } \\
\text { competiti- } \\
\text { veness }\end{array}$ \\
\hline 1 & Heat-integrated distillation & High & High & High \\
\hline 2 & Reactive distillation & High & High & High \\
\hline 3 & Membrane-assisted reactive distillation & High & High & High \\
\hline 4 & Microwave heating and drying & High & Low & High \\
\hline 5 & Continuous static mixer reactors & High & High & Medium \\
\hline 6 & Pulsed compression reactors & High & Low & Medium \\
\hline 7 & Centrifugal liquid-liquid contractors & High & Medium & Medium \\
\hline 8 & Rotor stator devices & High & Medium & Medium \\
\hline$\ldots$ & $\ldots$ & $\ldots$ & $\ldots$ & $\ldots$ \\
\hline $\mathrm{n}$ & Electric field-enhanced extraction & High & Low & Low \\
\hline & & & &
\end{tabular}

\subsection{TRIZ as a part of the Knowledge-Based Innovation (KBI)}

The classical TRIZ methodology is currently an important part of the Knowledge-Based Innovation and belongs to one of the most comprehensive, systematically organized invention knowledge and creative thinking methodologies (Cavallucci et al., 2015). In comparison with systematic eco-design tools and green innovation guidelines to assess and overcome negative environmental impacts, only TRIZ offers methods and tools for identification and elimination of engineering contradictions and helps dramatically enhance the inventive skills of engineers. TRIZ delivers scientifically founded and structured approach to forecast evolution of engineering systems and includes numerous tools and methods for product and process innovation. For example, the TRIZ Standard of the Association of German Engineers VDI 4521 (2016) contains 25 tools for definition of innovation objectives, problem formulation, idea generation and evaluation.

The TRIZ basic principle of Ideality, the resource-oriented and compromise-free problem solving fit in perfectly with the strategy of sustainable eco-innovation. On the one hand, the application of the TRIZ-based approaches helps identify and creatively solve eco-problems. On the other hand, TRIZ helps to mobilize resources of the existing processes and to reduce the negative environmental impact of technologies without efficiency losses.

Table 2. Top 10 inventive operators for reduction of energy consumption and losses in process intensification technologies and equipment

\begin{tabular}{|l|l|l|l|}
\hline Pos. & Inventive operator & Ranking & Parent TRIZ Inventive Principle \\
\hline 1 & 2a: Take out disturbing parts & 0,053 & 2. Leaving out / Trimming \\
\hline 2 & 29e: Heat transfer and exchange & 0,052 & 29. Pneumatic or hydraulic constructions \\
\hline 3 & 25b: Utilize waste resources & 0,041 & 25. Self-service \\
\hline 4 & 2e: Extract useful element. & 0,036 & 2. Leaving out / Trimming \\
\hline 5 & 5b: Combine functions & 0,034 & 5. Combining \\
\hline 6 & 10a: Prior useful function & 0,034 & 10. Prior action \\
\hline 7 & 22a: Utilize harm & 0,034 & 22. Converting harm into benefit \\
\hline 8 & 35d: Change temperature & 0,034 & 35. Transform physical and chem. properties \\
\hline 9 & 35a: Change aggregate state & 0,033 & 35. Transform physical and chem. properties \\
\hline 10 & 28a: Use electromagnetic fields & 0,032 & 28. Replace mechanical working principle \\
\hline
\end{tabular}

However, one universal ideation tool appears to be more convenient and favourable for the practical work with TRIZ. For this purpose, the classical TRIZ 40 Inventive Principles including 88 sub-principles (Altshuller, 1984) have been extended by the authors (Livotov et al., 2019a) with additional 72 subprinciples, extracted from standard solutions, evolution patterns, large number of PI equipment and methods, patents and research literature relevant for process engineering. This enhanced version of 40 Inventive Principles with in total 160 inventive operators is recommended for the systematic idea 
generation in Eco-AIDA. Table 2 illustrates the top 10 inventive operators for solving eco-problems in process intensification, primarily related to the high energy consumption and losses. The inventive operators are sorted by their mean occurrence frequency in the analysed 100 eco-patents and 58 thermal PI operations. The selection and ranking method proposed by the authors is disclosed in (Livotov et al., 2019c). A thorough analysis of the TRIZ efficiency for process intensification is given in (Livotov et al., 2018): among other outcomes, the application of the proposed TRIZ inventive operators in 6 industrial case studies resulted in 230 ideas and 26 patentable value added design concepts. In general, the identification and application of strongest inventive operators for different eco-problems appears to be a promising and more precise ideation technique within the Eco-AIDA toolbox.

\subsection{Eco-Design and sustainable manufacturing - body of knowledge}

In the last two decades numerous Eco-Design tools, methods, and approaches were developed to support the sustainable environmentally-friendly product design and manufacturing. Some of them are mentioned in Section 1. As outlined in (Fitzgerald et al., 2007), these tools may significantly vary depending on application field and information they require and process. The existing eco-design tools and methods address different sets of environmental metrics and objectives and provide different outcomes. Moreover, industrial companies need not only eco-design methods, but also their structured integration in the product development and manufacturing processes (Cluzel et al., 2014).

In the field of production engineering the Sustainable Manufacturing concept has been developed and is gaining now significantly more importance (Moldavska et al., 2017). As mentioned in (Roberts and Ball, 2014), there is a scientific and practical demand to structure the existing and continuously growing body of knowledge in the field sustainable engineering and manufacturing, including best practices, "good examples" of certain case studies, etc. Each industrial domain can benefit from such a database if the information can be collected, processed and retrieved easily. Thus, a library of crossindustry and interdisciplinary eco-tools, best-practices and examples of their application in process engineering is a part of the Eco-AIDA development. The next section of the paper illustrates problem definition techniques for eco-innovation process.

\section{PROBLEM DEFINITION IN ECO-INNOVATION PROCESS}

Process intensification, implementation of new technologies and eco-innovative solutions in process engineering often lead to additional negative side effects and secondary problems, resulting in engineering contradictions. In accordance to VDI 4521 (2016) the engineering contradiction is defined as a situation in which the improvement of one parameter (e.g. productivity) implies a deterioration of another parameter (e.g. manufacturing quality) within a system. In this context, the Eco-AIDA defines three types of contradictions in process engineering or other technical domains, as explained in Figure 2:

- non-eco engineering contradictions,

- primary eco-engineering contradictions,

- $\quad$ secondary eco-engineering contradictions.

A primary eco-engineering contradiction occurs when the improvement of a non-ecological engineering parameter (e.g. productivity) leads to a deterioration of an environmental characteristic in process or equipment (e.g. energy consumption), or vice versa. Consequently, a secondary ecoengineering contradiction is a situation where the improvement of one ecological parameter causes the worsening of another ecological parameter: for example, a new method of continuous recovery of acrylic acid (US20150203431A1) reduces energy consumption in the distilling process but leads to higher amount of waste water. In another example, the environmentally-friendly method for preparing ceramic powders disclosed in US8765261B2 decreases the amount of carbon waste but generates dust and thus requires additional measures to prevent air pollution. Especially the secondary ecocontradictions are not always evident for the engineers applying new technologies. It is also assumed that different types of engineering contradiction require specific problem solving or eco-ideation techniques. Therefore, this section has an emphasis on early identification and resolving of secondary eco-contradictions with following methods:

- correlation matrix of eco-requirements and identification of secondary problems,

- $\quad$ process mapping technique and problem ranking with the Importance-Satisfaction Analysis. 


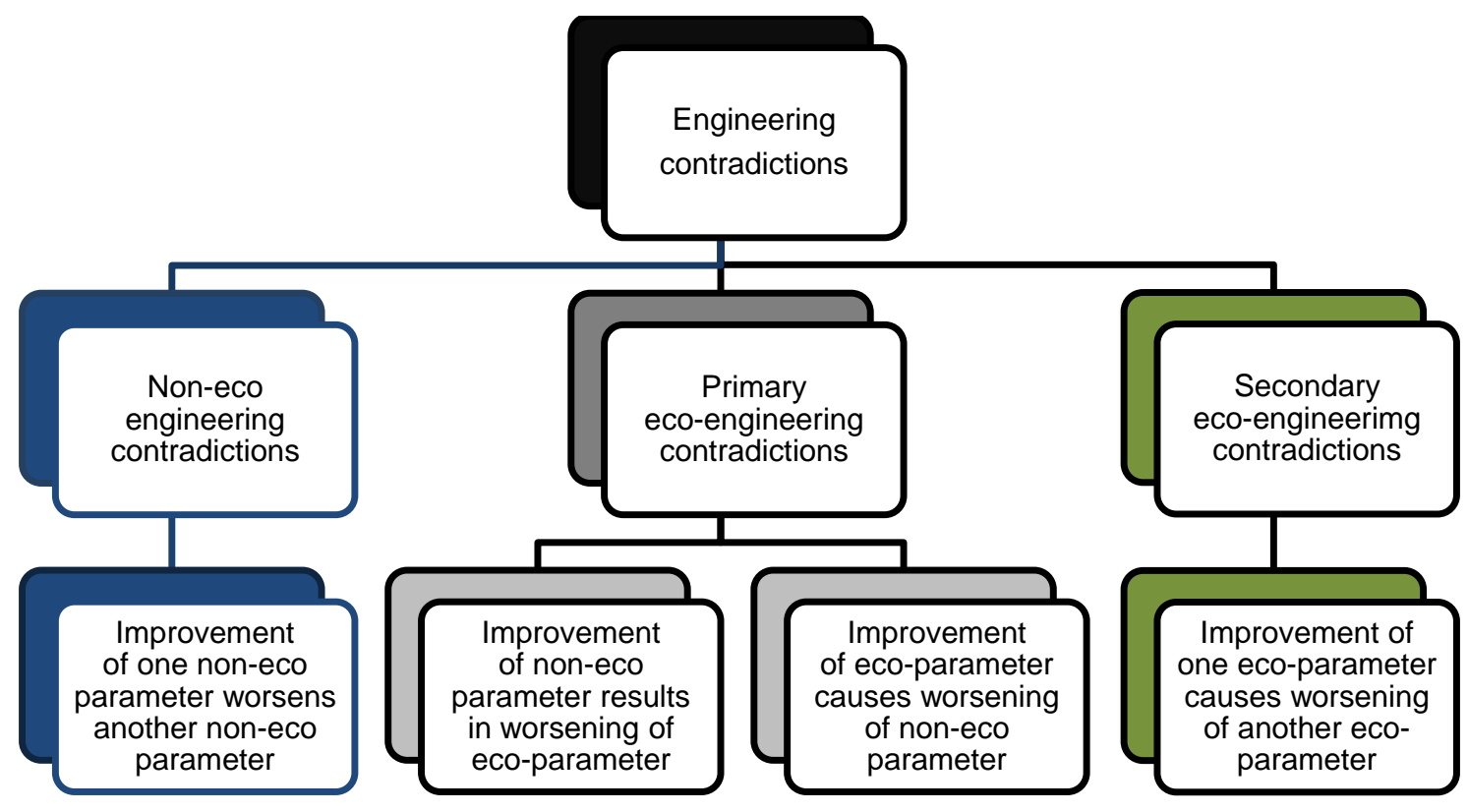

Figure 2. Types of engineering contradictions in process intensification

\subsection{Dynamic correlation matrix of Eco-Requirements}

The identification of the secondary eco-engineering contradictions requires definition of environmental parameters or eco-categories, such as Energy consumption, Air pollution, Acidification, Safety risks, etc., as presented in Section 2.1. These 14 environmental categories were defined through detailed analysis of PI technologies and 100 patent documents with ecological goals of inventions (Livotov et al., 2019c). For the identification of relationship between the environmental categories the original algorithm for secondary problem identification by patent analysis has been applied. The algorithm combines evaluation of the forward and backward patent citation trees with knowledgebased checklist of problems and expert assessment (Livotov et al., 2019b). The obtained information about existing correlations between the initial eco-problems of the inventions and the corresponding secondary eco-problems helps to build a correlation matrix predicting secondary eco-contradictions in the field of analysis. Contrary to the deterministic definition of contradictions used in TRIZ, the identified contradictions are expected here with a certain degree of probability. A fragment of the correlation matrix with 14 environmental categories is presented in Table 3, where "-1" indicates a possible secondary eco-contradiction, and " +1 " outlines a positive synergetic effect.

Table 3. Fragment of the correlation matrix with identified problems and secondary ecocontradictions: "-1" negative impact (eco-contradiction); "+1" positive impact; "0" - neutral.

Eco-parameters

to be improved:

to be improved:
\begin{tabular}{|l|l|l|l|l|l|l|l|l|l|l|l|l|}
\hline 1 & Energy consumption & & -1 & +1 & -1 & -1 & -1 & +1 & +1 & +1 & -1 & +1 \\
\hline 2 & Air pollution & -1 & & +1 & -1 & -1 & -1 & -1 & +1 & +1 & -1 & -1 \\
\hline 3 & Acidification & -1 & +1 & & -1 & 0 & -1 & -1 & +1 & +1 & 0 & +1 \\
\hline 4 & Safety risks & -1 & -1 & 0 & & -1 & -1 & +1 & +1 & 0 & -1 & -1 \\
\hline 5 & Chemical waste disposal & -1 & -1 & 0 & +1 & & +1 & +1 & +1 & 0 & 0 & 0 \\
\hline 6 & Depletion of abiotic resources & -1 & -1 & +1 & 0 & +1 & & +1 & +1 & +1 & -1 & +1 \\
\hline 7 & Toxicity & +1 & -1 & 0 & +1 & +1 & +1 & & +1 & 0 & +1 & 0 \\
\hline 8 & Eutrophication & +1 & +1 & +1 & +1 & +1 & +1 & +1 & & +1 & 0 & 0 \\
\hline 9 & Photochemical oxidation & +1 & -1 & +1 & 0 & -1 & -1 & 0 & +1 & & 0 & 0 \\
\hline 10 & Water pollution & +1 & +1 & 0 & 0 & 0 & +1 & +1 & 0 & 0 & & 0 \\
\hline 11 & Solid Waste & -1 & +1 & +1 & +1 & -1 & +1 & 0 & 0 & 0 & -1 & \\
\hline
\end{tabular}


The correlation matrix helps engineers to see how one improved eco-parameter can affect the other ecoparameters either positively or negatively. For instance, reduction of Toxicity (7) has a positive impact on Water pollution (10) but can negatively affect Air pollution (2), for example, by use of sorbents. The presented 14x14 correlation matrix can be dynamically displayed with higher resolution with a large number of individual eco-requirements, giving more precise recommendations for possible secondary ecoengineering contradictions. Such a dynamic correlation matrix based on patent analysis can combine various levels of abstractions or generalization and increase the accuracy and reliability of ecological impact assessments for new technologies. Based on the same principle a correlation matrix with non-eco parameter and eco-parameter can be designed and applied for the identification of primary ecocontradiction or non-eco contradictions. Table 4 illustrates 27 parameters for another correlation matrix extracted from 150 patent documents related to the granulation process (Livotov et al, 2019b).

Table 4. Parameters of the correlation matrix for granulation process extracted from patents

\begin{tabular}{ll|ll}
\hline N & Parameter & N & Parameter \\
\hline 1 & Process duration, time expenditures & 15 & Binder or additive consumption \\
2 & Quality of product (cracks...) & 16 & Size or volume of equipment \\
3 & Energy consumption & 17 & Solid handling efforts (transporting ...) \\
4 & Water consumption & 18 & Controllability of the process \\
5 & Uniformity of granulation product & 19 & Adaptability of equipment \\
6 & Complexity of process or equipment & 20 & Production capacity \\
7 & Costs (investments, installation...) & 21 & Product composition \\
8 & Maintenance and cleaning & 22 & Process efficiency (mass balance...) \\
9 & Productivity or yield & 23 & Mechanical properties (hardness...) \\
10 & Reliability of equipment and process & 24 & Chemical properties (bioavailability ...) \\
11 & Disintegration, solubility, dispersion... & 25 & Physical properties (density ...) \\
12 & Agglomeration (solidification...) & 26 & Homogeneity of product \\
13 & Moisture content & 27 & Replaceability of equipment \\
14 & Environmental performance & 28 & Others \\
\hline
\end{tabular}

\subsection{Process mapping and problem ranking}

The findings from the correlation matrix and patent analysis can be verified using the process mapping. However, this method delivers reliable results for existing technologies or well-known processes. Process mapping is an easy-to-use technique to identify eco-problems and innovation tasks, formulated as solutionneutral process intensification requirements. The method involves breaking down of a complete industrial production process into process steps to capture in each step the information on process equipment, processing methods, input/output quality parameters, product, available resources, and environment. Process mapping results in comprehensively capturing and ranking of all existing problems, needs, requirements and possible improvements or optimisation opportunities of the technologies and equipment in each process step and in production process in whole.

The identification of all positive and negative functions and corresponding effects is the basis for the formulation of a complete list of the solution-neutral requirements as innovation tasks. These tasks can be separated in three types of problems: a) enhancement of positive functions or effects, b) elimination of negative functions, effects or undesired properties, c) raising degree of controllability, accuracy, and automation of the process step. As the number of issues for each process step can be between 10 and 40 or even more, the proposed problem ranking technique helps to identify issues with higher need for action, using problem ranking with the Importance-Satisfaction Analysis. In accordance to the original calculation method a higher ranking values are assigned to the issues with higher importance and lower satisfaction metrics. Moreover, the pair-by-pair comparisons of two issues allow to systematically identify all possible engineering contradictions. An example of the problem ranking technique in process engineering including the calculation algorithm is presented in (Casner and Livotov, 2017).

For example, the application of the process mapping in two industrial case studies dealing with continuous drying in the pharmaceutical industry and granulation in the ceramic industry resulted in identification of 55 engineering and 22 environmental problems (Livotov et al., 2019c). The 
environmental problems were primarily related to the energy consumption category (36\%), followed by the air pollution (32\%), water pollution and consumption (23\%), and raw material losses (9\%).

\section{CONCLUSION AND OUTLOOK}

Since the implementation of environmentally-friendly technologies in process engineering often results in negative technical and environmental side effects, additional methodological efforts are required to reduce environmental issues while increasing economic and technical benefits. The paper conceptualises a comprehensive approach Eco-AIDA for eco-innovation and eco-design in process engineering for efficient integrated upstream and downstream processes. The approach combines the advantages of Process Intensification as a Knowledge-Based Engineering (KBE) methodology, inventive tools of Knowledge-Based Innovation (KBI) with TRIZ methodology, and main principles and best-practices of Eco-Design and Sustainable Manufacturing. It includes a process mapping technique, a correlation matrix for identification eco-engineering contradictions, re-organised database of Process Intensification methods and equipment, as well as a set of strongest the TRIZ-based inventive operators for eco-ideation. The future research should be focused on

- definition of the eco-innovation process in the domain of process engineering,

- adaptation of the Process Intensification databases for eco-innovation,

- further development, optimization and computerization of the toolbox for the eco-innovation process,

- $\quad$ application of the Eco-AIDA tools for the integrated upstream and downstream processes and validation through the case studies,

- development of learning resources for dissemination of major outcomes to the current and next generation of engineers.

Even if the application of the Eco-AIDA is limited to the domain of process engineering, its basic principles and tools can be recommended for the other domains of eco-innovation.

\section{REFERENCES}

Altshuller, G.S. (1984), Creativity as an exact science: the theory of the solution of inventive problems, Gordon and Breach Science Publishers, New York, ISSN 0275-5807.

Azzaro-Pantel, C. (2015), "Green Process Engineering Design Methodology: A Multicriteria Approach,” In: Poux, M., Cognet, P., Gourdon, C. (Eds.), Green Process Engineering: From Concepts to Industrial Applications, CRC Press, Boca Raton, pp. 3-26, ISBN 9781482208177.

Benali, M. and Kudra, T. (2008), "Drying process intensification: application to food processing". Available at: https://www.researchgate.net/publication/266211018. Accessed on 11.11.2018.

de Bont, C., den Ouden, P.H., Schifferstein, H.N.J., Smulders, F.E.H.M. and van der Voort, M. (2013), Advanced design methods for successful innovation, Design United, Den Haag.

Boodhoo, K. and Harvey, A. (2013), "Process Intensification: An overview of principles and practice," In: Boodhoo, K. and Harvey, A. (Eds.), Process Intensification for Green Chemistry, John Wiley \& sons, pp. 1-31. https://doi.org/10.1002/9781118498521.ch1

Calza, F., Parmentola and A., Tutore, I. (2017), "Types of Green Innovations: Ways of Implementation in a NonGreen Industry”, Sustainability, Vol. 9, No. 8 p. 1301. https://doi.org/10.3390/su9081301

Casner, D. and Livotov, P. (2017), “Advanced innovation design approach for process engineering”, 21st International Conference on Engineering Design (ICED 17), Vol 4: Design Methods and Tools, Vancouver, Canada, 21-25.08.2017, pp. 653-662, ISBN 978-1-904670-92-6.

Cavalluci, D., Cascini, G., Duflou, J., Livotov, P. and Vaneker, T. (2015), “TRIZ and Knowledge-Based Innovation in Science and Industry", Procedia Engineering, Vol. 131, pp. 1-2. https://doi.org/10.1016/j.proeng.2015.12.341

Chen, J.L. (2002), “Green evolution rules and ideality laws for green innovative design of products," Fourth international symposium on going green-care innovation, Vienna, pp. 130-134.

Cluzel, F., Vallet, F., Tyl, B., Bertoluci, G. and Leroy, Y. (2014), "Eco-design vs. eco-innovation: an industrial survey," 13th Int. Design Conference - DESIGN 2014, Dubrovnik, pp.1501-1510.

Cross, W.T. and Ramshaw, C. (1986), "Process intensification: laminar flow heat transfer", Chemical Engineering Research and Design, Vol. 64, pp. 293-301.

European Commission (2018), "Efficient integrated downstream processes," Research and Innovation, Available at: http://ec.europa.eu/research/participants/portal/desktop/en/opportunities/h2020/topics/ce-spire-042019.html (29.11.2018). 
Ferrer, J.B., Negny, S., Robles, G.C. and Le Lann, J.M. (2012), "Eco-innovative Design Method for Process Engineering”, Computers \& Chemical Engineering, Vol. 45, pp. 137-151.

Fitzgerald, D.P., Herrmann, J.W., Sandborn, P.A., Schmidt, L.C., Gogoll, T.H. (2007), "Design for Environment (DfE): Strategies, Practices, Guidelines, Methods, and Tools,” In: Kutz, M. (Ed.), Environmentally Conscious Mechanical Design, Wiley, Hoboken, New Jersey.

Fresner, J., Jantschgi, J., Birkel, S., Barnthaler, J. and Krenn, C. (2010), "The theory of inventive problem solving (TRIZ) as option generation tool within cleaner production projects”, Journal of Cleaner Production, Vol. 18, No. 2, pp. 128-136.

Fussler, C. and James, P. (1996), Driving eco-innovation: a breakthrough discipline for innovation and sustainability, London Pitman Publishing, Washington DC.

GE Healthcare Bio-Sciences AB. (2016), "Unlocking the potential for efficiency in downstream bioprocesses", Available at: http://www.processdevelopmentforum.com/ppts/posters/WP29195721_Process_ intensification.pdf (12.11.2018).

Keil, F.J. (2018), "Process intensification,” Reviews in Chemical Engineering, Vol. 34 No. 2, pp. 135-200. https://doi.org/10.1515/revce-2017-0085

Law, R., Ramshaw, C. and Reay, D. (2017), "Process intensification - overcoming impediments to heat and mass transfer enhancement when solids are present, via the IbD project", Thermal Science and Engineering Progress, pp. 53-58. https://doi.org/10.1016/j.tsep.2017.02.004

Lindahl, M., and Ekermann, S. (2013), “Structure for Categorization of EcoDesign Methods and Tools," In: Andrew, Y.C. Nee, Bin Song, Soh-Khim Ong (Eds.), Re-engineering Manufacturing for Sustainability: Proceedings of the 20th CIRP International Conference on Life Cycle Engineering, Springer Science \& Business Media, Singapore, 17-19 April, 2013, pp. 117-122. https://doi.org/10.1007/978-981-4451-48-2_19

Livotov, P., Mas'udah and Chandra Sekaran, A.P. (2018), “On the Efficiency of TRIZ Application for Process Intensification in Process Engineering”, In: Cavallucci, D., de Guio, R., Koziołek, S. (Eds.), Automated Invention for Smart Industries, IFIP Advances in Information and Communication Technology, Vol. 541, Springer, Cham, pp.126-140. https://doi.org/10.1007/978-3-030-02456-7_11

Livotov, P., Chandra Sekaran, A.P., Law, R., Mas'udah and Reay, D. (2019a), "Systematic Innovation in Process Engineering: Linking TRIZ and Process Intensification.” In: Chechurin, L., Collan, M. (Eds.), Advances in Systematic Creativity, Palgrave Macmillan, Cham, pp. 27-44. https://doi.org/10.1007/978-3319-78075-7_3

Livotov, P., Mas'udah, Sarsenova, A. and Chandra Sekaran, A.P. (2019b), "Identification of Secondary Problems of New Technologies in Process Engineering by Patent Analysis," In: Chechurin, L., Collan, M. (Eds.), Advances in Systematic Creativity, Palgrave Macmillan, Cham, pp. 151-166. https://doi.org/10.1007/978-3-319-78075-7_10

Livotov, P., Chandra Sekaran, A.P., Mas'udah, Law, R., Reay, D., Sarsenova, A. and Sayyareh, S. (2019c), "Eco-innovation in Process Engineering: Contradictions, Inventive Principles and Methods", Thermal Science and Engineering Progress, Vol. 9, No. 2019, pp. 52-65. https://doi.org/10.1016/j.tsep.2018.10.012

Moldavska, A. and Welo, T. (2017), "The concept of sustainable manufacturing and its definitions: A contentanalysis based literature review”, Journal of Cleaner Production, Vol. 166, pp. 744-755. https://doi.org/10.1016/j.jclepro.2017.08.006

Pahl, G. and Beitz, W. (1996), Engineering Design: A Systematic Approach, Springer, Berlin. https://doi.org/10.1007/978-1-4471-3581-4

Patrasacu, I., Bildea, C.S. and Kiss, A.A. (2018), "Eco-efficient downstream processing of bio-butanol by enhanced process intensification and integration", ACS Sustainable Chemistry and Engineering, Vol. 6 No. 4, pp. 5452-5461. https://doi.org/10.1021/acssuschemeng.8b00320

Poux, M., Cognet, P. and Gourdon, C. (2015), Green Process Engineering: From Concepts to Industrial Applications, CRC Press, Boca Raton, ISBN 9781482208177.

Reay, D., Ramshaw, C. and Harvey, A. (2013), Process Intensification, Butterworth-Heinemann, Oxford.

Roberts, S.J.F. and Ball, P.D. (2014), "Developing a library of sustainable manufacturing practices", 21 st CIRP Conference on Life Cycle Engineering, Procedia CIRP, Vol. 15, pp.159 - 164.

Russo, D., Schofer, M. and Bersano, G. (2015), "Supporting ECO-innovation in SMEs by TRIZ Ecoguidelines”, Procedia Engineering, Vol. 131, pp. 831-839.

Russo, D. and Serafini, M. (2015), "Anticipating the identification of contradictions in eco-design problems", Procedia Engineering, Vol. 131, pp.1011-1020.

Tyl, B., Legardeur, J., Millet, D. and Vallet, F. (2014), “A comparative study of ideation mechanisms used in eco-innovation tools", Journal of Engineering Design, Vol. 25 No. 10-12, pp. 325-345. https://doi.org/10.1080/09544828.2014.992772

VDI (2016), VDI Standard 4521. Inventive problem solving with TRIZ. Fundamentals, terms and definitions, Beuth, Berlin.

Wang, H., Mustaffar, A., Phan, A.N., Zivkovic, V., Reay, D., Law, R. and Boodhoo, K. (2017), "A review of process intensification applied to solids handling", Chemical Engineering and Processing: Process Intensification, Vol. 118, pp.78-107. https://doi.org/10.1016/j.cep.2017.04.007 